Check for updates

Cite this: RSC Adv., 2018, 8, 28879

\title{
Synthesis of ZSM-5/KIT-6 with a tunable pore structure and its catalytic application in the hydrodesulfurization of dibenzothiophene and diesel oil
}

\begin{abstract}
Qi Gao, ${ }^{a}$ Yan Zhang, $\dagger^{a}$ Kangdi Zhou, ${ }^{a}$ Huadong Wu, (D) *a Jia Guo, ${ }^{* a}$ Linfeng Zhang, ${ }^{a}$ Aijun Duan, (D) ${ }^{b}$ Zhen Zhao, (D) ${ }^{b}$ Fuqing Zhang ${ }^{a}$ and Yuxin Zhou ${ }^{a}$

Porous support materials were prepared by assembling primary and secondary ZSM-5 structural units into a well-ordered mesoporous framework. The materials possessed both ZSM-5 microporous building units and mesoporous structure were used as supports for the preparation of hydrodesulfurization (HDS) catalysts. The materials and their corresponding catalysts were characterized by XRD, FTIR, ${ }^{27}$ Al MAS NMR, TEM, $\mathrm{N}_{2}$ adsorption-desorption, Py-FTIR, $\mathrm{H}_{2}$-TPR, Raman, and HRTEM techniques. The pore structures of the composite materials were modulated by adjusting the molar ratio of butanol/P123 $(\mathrm{BuOH} / \mathrm{P} 123)$ and then, the influences of $\mathrm{BuOH} / \mathrm{P} 123$ on the catalytic performance in the HDS of dibenzothiophene (DBT) and diesel oil were systematically studied. The results showed that butanol has a big influence on the structure of the micro-mesoporous material, whereby different micromesoporous structures, such as the $p 6 \mathrm{~mm}$ hexagonal structure or la $\overline{3} d$ cubic structure, were formed with different butanol addition amounts. The composite ZK-3 $(\mathrm{BuOH} / \mathrm{P} 123=100)$ possessed the best surface area and pore structure. Therefore, the NiMo/ZK-3 catalyst showed the highest catalytic activity in the HDS of DBT with a BP selectivity of $72.1 \%$ due to its excellent textural property, moderate MSI, relatively high $\mathrm{B} / \mathrm{L}$ ratios, and highly dispersed NiMoS active phases. Moreover, the NiMo/AZK-3 catalyst exhibited excellent catalytic performance in the HDS of diesel oil.
\end{abstract}

Received 3rd July 2018

Accepted 31st July 2018

DOI: $10.1039 / \mathrm{c} 8 \mathrm{ra0} 5675 \mathrm{~g}$

rsc.li/rsc-advances can greatly improve the desulfurization performance of a catalyst. $^{\mathbf{1 1 , 1 2}}$ Therefore, many mesoporous materials are applied as catalyst supports, such as MCM-41, ${ }^{13,14}$ MCM-36, ${ }^{15}$ SBA-15 (ref. 16-20), KIT-6. ${ }^{21}$ Kim et al. ${ }^{22,23}$ successfully synthesized KIT-6 (6$12 \mathrm{~nm}$ ) mesoporous material with an $I a \overline{3} d$ cubic structure by employing $\mathrm{P} 123$ together with $n$-butanol $(\mathrm{BuOH})$ as mixed templating agents. The material was demonstrated to have connecting pores $(\sim 1.7 \mathrm{~nm})$ besides two sets of threedimensional (3D) helical main channels. An interactive netlike structure was formed between the main channel, which evidently promoted the diffusion and reaction of large molecules. This novel kind of material KIT- 6 with thick pore walls, high hydrothermal stability, and a high specific surface area has aroused great attention for its potential applications in different catalysis processes. $^{24}$

However, the lack of B acid cites has limited the wide application of pure mesoporous materials. In order to promote the acidity, on the one hand, mesoporous zeolite Y, Beta, and ZSM-5 were synthesized. ${ }^{8}$ Fu et al. prepared different kinds of mesoporous material-supported HDS catalysts; the resulting catalysts all exhibited high activities in the HDS of 4,6-DMDBT compared with $\gamma-\mathrm{Al}_{2} \mathrm{O}_{3}$-supported Pd catalysts. ${ }^{8}$ On the other hand, building units of microporous zeolite were introduced into the framework
${ }^{a}$ Key Laboratory of Green Chemical Process of Ministry of Education, Hubei Key Laboratory of Novel Chemical Reactor and Green Chemical Technology, Wuhan Institute of Technology, Wuhan 430073, P. R. China.E-mail: wuhuadong@wit.edu. cn; guojia@wit.edu.cn; Tel: +86-027-87194980

${ }^{b}$ State Key Laboratory of Heavy Oil Processing, China University of Petroleum, Beijing, P. R. China

$\dagger$ This author has equal contribution as the first author. 
of the mesoporous wall, thus they are named micro-mesoporous composite materials. Different varieties of these kinds of materials have been used as supports to prepare HDS catalysts, including MFI/MCM-41, ${ }^{25}$ Beta-KIT-6 (BK), ${ }^{26}$ and L-KIT-6 (LK). ${ }^{27}$ Österholm et al. prepared the micro-mesoporous composite material MFI/MCM-41 by a nano-assembly method..$^{28}$ The results showed that with increasing the $\mathrm{Al}$ content in the composite, the total acid and B acid were increased at the same time, and the degree the mesostructure was retained was higher than that of pure MCM-41 when the composite material was calcined at 1173 $\mathrm{K}$, which indicated that the introduction of micropores into the mesoporous composite improved the stability of the material. ${ }^{28}$ Zhang $^{26}$ synthesized the micro-mesoporous material BK, which contained both a Beta and KIT- 6 bimodal pore distribution. The catalytic performance of NiMo/BK over DBT was much better than that of both NiMo/Beta and NiMo/KIT-6. CoMo/LK prepared by Duan et al. ${ }^{27}$ possessed a similar mesoporous structure of CoMo/KIT-6, and it was found that the HDS efficiency of benzothiophene (BT) over the CoMo/LK catalyst was higher than that of CoMo/KIT-6 at all liquid hourly space velocities (LHSVs), and about twice that of CoMo/L. All of this indicated that micromesoporous materials, which combine the advantage of a porous structure and acidity, were beneficial to the diffusion of sulfides with a large molecular size and enhanced the HDS catalytic performances of catalysts. Among the different kinds of zeolites, nanocrystalline ZSM-5 is a versatile material due to its excellent hydrogenation and isomerization performance. In our previous work, we found that mesoporous KIT-6 silica-enwrapped nanosized ZSM-5 zeolite crystals were an efficient HDS catalyst support, ${ }^{29}$ and that the acidities and diffuse properties of the composites were much stronger than those of the mechanical mixtures of ZSM-5 and KIT-6. Therefore, the micro-mesoporous material ZSM-5/KIT-6 (ZK), prepared by assembling the ZSM-5 primary and secondary building units into the framework of the KIT- 6 mesoporous structure, may have better performance than the composite we prepared before.

Though KIT- 6 based micro-mesoporous materials of BetaKIT-6 and L-KIT-6 have previously been synthesized successfully, the role of mixing in a structure-directing template has not yet been studied deeply, to the best of our knowledge, especially the molar ratio of $\mathrm{BuOH} / \mathrm{P} 123$. Specifically, as far as we know, there are no reports about how to change the pore structure of the novel micro-mesoporous material ZK by changing the ratio of $\mathrm{BuOH} / \mathrm{P} 123$. Consequently, we synthesized the composite material ZK using a two-step hydrothermal crystallization method by assembling the nano-sized ZSM-5 precursor into a well-ordered $I a \overline{3} d$ cubic mesoporous structure in this work. In order to modulate the physicochemical properties of the micro-mesoporous material ZK to ensure that the novel material has an open pore structure, a series of composites were prepared with different amounts of $n$-butanol. The as-synthesized ZK materials were then employed as supports to prepare different NiMosupported catalysts, notably, a series of catalysts were evaluated over DBT and diesel oil for the first time. NiMo supported on ZSM-5, KIT-6, and $\mathrm{Al}_{2} \mathrm{O}_{3}$ catalysts were also prepared for comparison.

\section{Experimental}

\subsection{Synthesis of the supports}

2.1.1 Synthesis of the ZK materials. Micro-mesoporous material ZSM-5/KIT-6 (denoted as ZK) was prepared under hydrothermal condition using the ZSM-5 microcrystalline emulsion as a precursor and P123 together with $n$-butanol as mesoporous templates. First, the ZSM-5 microcrystalline emulsion precursor was prepared based on the literature. ${ }^{30}$ Under room temperature, $26.2 \mathrm{~g}$ tetrapropylammonium hydroxide (TPAOH) was mixed with $20 \mathrm{~g}$ deionized water, with stirring for $0.5 \mathrm{~h}$, then $0.4 \mathrm{~g} \mathrm{Al}(\mathrm{O}-\mathrm{i}-\mathrm{Pr})_{3}$ and $0.2 \mathrm{~g} \mathrm{NaOH}$ were added. After complete dissolution, $6.12 \mathrm{~g}$ tetraethyl orthosilicate (TEOS) was added dropwise into the clear solution, and the mixed solution was stirred for $16 \mathrm{~h}$. The final solid-liquid mixture of $\mathrm{SiO}_{2} / \mathrm{Al}_{2} \mathrm{O}_{3} / \mathrm{NaOH} / \mathrm{TPAOH}$ with a molar ratio of $30 / 1$ / $5.1 / 33$ was shifted to a Teflon kettle under $150{ }^{\circ} \mathrm{C}$ for $24 \mathrm{~h}$. Second, $2 \mathrm{~g}$ pluronic P123 was dissolved in a mixture of $57 \mathrm{~g}$ $\mathrm{H}_{2} \mathrm{O}$ and $19 \mathrm{~g}$ of $2 \mathrm{M}$ hydrochloric acid solution at $35^{\circ} \mathrm{C}$, and the solution was stirred for about $4 \mathrm{~h}$, ensuring that the P123 was completely dissolved. Then, $2.56 \mathrm{~g} n$-butanol was added into the obtained solution, with stirring continuously for $1 \mathrm{~h}$. Third, the above ZSM-5 microcrystalline emulsion (containing $0.98 \mathrm{mmol}$ of $\mathrm{Al}_{2} \mathrm{O}_{3}$ and $29.4 \mathrm{mmol}$ of $\mathrm{SiO}_{2}$ ) and $12.24 \mathrm{~g}$ TEOS were mixed with the P123 solution. The obtained homogeneous gel was $1 \mathrm{Al}_{2} \mathrm{O}_{3}: 90 \mathrm{SiO}_{2}: 0.35 \mathrm{P} 123: 35.24 \mathrm{BuOH}: 38 \mathrm{HCl}$. The gel was agitated vigorously for $24 \mathrm{~h}$ at $35^{\circ} \mathrm{C}$, and then was moved to an autoclave kettle for crystallization at $100{ }^{\circ} \mathrm{C}$ for $24 \mathrm{~h}$. After the autoclave kettle was cooled down to ambient temperature, the solid product was obtained through filtration, washing, and drying at $100{ }^{\circ} \mathrm{C}$ for $10 \mathrm{~h}$. After that, the sample was calcinated at $550{ }^{\circ} \mathrm{C}$ with a programmed heating system to remove the template. The composite materials $\mathrm{ZK}$ with varying molar ratios of $\mathrm{BuOH} / \mathrm{P} 123$ (80, 90, 100, and 120) were denoted as ZK-1, ZK-2, $\mathrm{ZK}-3$, and ZK-4. A schematic representation of the synthesis of the ZK composite is shown in Fig. 1.

2.1.2 Synthesis of the reference materials. ZSM-5 zeolite $\left(\mathrm{SiO}_{2}: \mathrm{Al}_{2} \mathrm{O}_{3}\right.$ molar ratio of 90 ) was prepared in the same way as described above, but the crystallization temperature and time were extended to $170{ }^{\circ} \mathrm{C}$ and $48 \mathrm{~h}$, respectively. Mesoporous silica KIT- 6 was prepared based on the reported literature..$^{22,31}$

\subsection{Preparation of the NiMo-supported catalysts}

The NiMo-supported catalysts were prepared by a two-step incipient-wetness impregnation method. First, the obtained

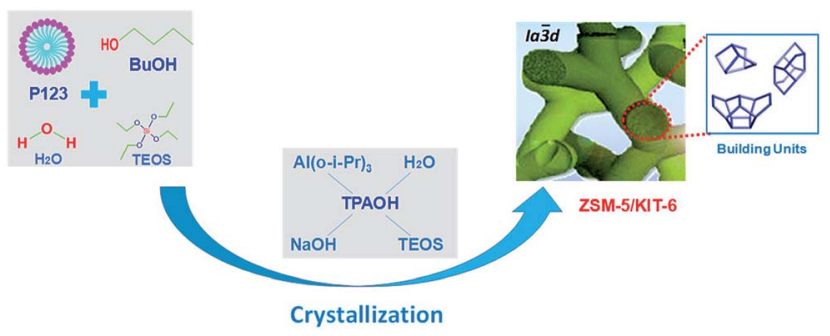

Fig. 1 Schematic representation of the synthesis of the ZK composite. 
ZK materials were ion exchanged with $1.0 \mathrm{M}$ ammonium chloride solution at $80{ }^{\circ} \mathrm{C}$ for $2 \mathrm{~h}$, and then the composites were filtered, washed, dried, and calcinated in the same way as described above. Mo and Ni were then impregnated, respectively. Calcination was carried out after each impregnation. Finally, catalysts with $10 \mathrm{wt} \% \mathrm{MoO}_{3}$ loading and $3.5 \mathrm{wt} \% \mathrm{NiO}$ loading were prepared. Meanwhile, $\mathrm{NiMo} / \mathrm{Al}_{2} \mathrm{O}_{3}, \mathrm{NiMo} / \mathrm{ZSM}-5$, and NiMo/KIT-6 catalysts with the same loading of active metals were also prepared as reference catalysts. In addition, a part of the synthesized materials was mixed with $\mathrm{Al}_{2} \mathrm{O}_{3}$, whereby the weight of $\mathrm{Al}_{2} \mathrm{O}_{3}$ was four times that of the synthesized materials. Those $\mathrm{Al}_{2} \mathrm{O}_{3}$-doped mixtures were also used as supports to prepare NiMo-supported catalysts, which were only used for the HDS of diesel oil, and these mixtures of supported NiMo catalysts were denoted as NiMo/AZK-1, NiMo/AZK-2, NiMo/AZK-3, NiMo/AZK-4, NiMo/AZSM-5, and NiMo/AKIT-6.

\subsection{Characterization of the supports and catalysts}

Wide-angle X-ray diffraction (XRD) patterns of the supports and catalysts were tested using an X-ray diffractometer (D8 ADVANCE and DAVINCI DESIGN) using CuK $\alpha(40 \mathrm{kV}, 40 \mathrm{~mA})$ radiation in the $2 \theta$ range from $5-90^{\circ}$ at a scanning rate of $1^{\circ} \min ^{-1}$. For small-angle XRD, the samples were tested on a diffractometer of PANalytical B.V. (X'Pert PRO) using CuK $\alpha$ (60 $\mathrm{kV}, 55 \mathrm{~mA}$ ) radiation. Here, $2 \theta$ ranged from $0.5-5^{\circ}$. FTIR absorbance spectra were recorded using a Nicolet 6700 spectrometer (American Thermo Electron) with the wavenumber range $1200-400 \mathrm{~cm}^{-1}$. The detected slices were handled by $\mathrm{KBr}$ tabletting with a weight ratio of $100 \mathrm{KBr}: 1$ sample. ${ }^{27} \mathrm{Al}$ MAS NMR spectra were recorded with a Bruker Avance III $500 \mathrm{MHz}$ spectrometer at $130 \mathrm{MHz}$ with a $0.9 \mu$ s pulse width, $6 \mu$ s delay time, and $12 \mathrm{kHz}$ spinning speed. TEM images were detected on a JEOL JEM 2100 electron microscope with a testing voltage of $200 \mathrm{kV}, \mathrm{Cs}=0.5 \mathrm{~mm}$. Before testing, the materials were ground in an agate mortar, and subsequently dispersed in absolute ethanol under ultrasonic conditions for about $20 \mathrm{~min}$. After that, two drops of the supernatant liquid were dripped on to an ultrathin copper grid coated with a sputtered carbon polymer. The textural properties of the synthesized materials were obtained by nitrogen adsorption-desorption with ASAP 2020 at $-196{ }^{\circ} \mathrm{C}$. The specific surface areas of these materials were calculated by the BET model. The pore size distribution (PSD) was acquired from the desorption branch of the isotherms using the BJH method. The total pore volumes were gained from the amounts of nitrogen absorbed at a relative pressure $\mathrm{P} / \mathrm{P}_{0}$ of 0.98 . The acidity of the catalysts were taken from pyridine-FTIR (Py-FTIR) spectroscopy on a MAGNAIR 560 FTIR instrument (Nicolet Co., US) with a resolution of $1 \mathrm{~cm}^{-1}$. The samples were pretreated under $500{ }^{\circ} \mathrm{C}$ for $5 \mathrm{~h}$ with a vacuum of $1.33 \times 10^{-3} \mathrm{~Pa}$, and subsequently absorbed pyridine vapor at room temperature for $20 \mathrm{~min}$. Then, the system was degassed at $473 \mathrm{~K}$ and $623 \mathrm{~K}$ respectively, and the IR spectra were recorded at the same time. $\mathrm{H}_{2}$-TPR analyses were performed on a Quantachrome apparatus (Autosorb-iQ, USA). Here, $100 \mathrm{mg}$ sample was pretreated under air atmosphere by calcination at $300{ }^{\circ} \mathrm{C}$ for $1 \mathrm{~h}$ and subsequently cooled to $30{ }^{\circ} \mathrm{C}$. Then, $10 \% \mathrm{H}_{2} /$ Ar flow $\left(40 \mathrm{ml} \mathrm{min}^{-1}\right)$ was passed over the catalyst bed while the temperature was ramped from $30{ }^{\circ} \mathrm{C}$ to $600{ }^{\circ} \mathrm{C}$ at a heating rate of $10{ }^{\circ} \mathrm{C} \mathrm{min}{ }^{-1}$. The hydrogen consumption signal was recorded by a TCD detector. The Raman shift spectra were performed on a Raman spectrometer (Renishaw Micro-Raman System 2000) operating at a laser wavelength of $325 \mathrm{~nm}$. The wave number ranged from 1600 to $200 \mathrm{~cm}^{-1}$. The size of the laser spot was about $1-2 \mathrm{~mm}$ with a power of $8 \mathrm{~mW}$. The HRTEM images were observed through a Philips Tecnai G2 F20 S-TWIN system. The catalysts were presulfided in a flow of cyclohexane containing $2.5 \mathrm{wt} \%$ $\mathrm{CS}_{2}$ at $340{ }^{\circ} \mathrm{C}$ for $4 \mathrm{~h}$ to make sure that the molybdenum oxide was exchanged to NiMoS. After that, the sulfided catalysts were collected and sealed in cyclohexane to prevent oxidation.

\subsection{Catalyst evaluation}

The catalytic performances of the different NiMo/ZK catalysts were investigated using DBT (dissolved in cyclohexane with $600 \mathrm{ppm} \mathrm{S}$ ) as the reactant molecule. The catalysts were presulfided first under a $\mathrm{H}_{2}$ flow at $320{ }^{\circ} \mathrm{C}, 4 \mathrm{MPa}$. The presulfided process lasted for about $4 \mathrm{~h}$. The catalyst weight was $0.5 \mathrm{~g}$; then the particle size of the catalysts and quartz sand were all crushed to 40-60 mesh. HDS reactions were carried out at $4 \mathrm{MPa}$ and $340{ }^{\circ} \mathrm{C}$ with a $\mathrm{H}_{2} /$ oil ratio of $200 \mathrm{ml} \mathrm{ml}^{-1}$. The reaction products were analyzed by offline Finnigan Trace GC-MS with a Trace Ultral gas chromatograph using a HP-5MS $(60 \mathrm{~m} \times$ $0.25 \mathrm{~mm} \times 0.25 \mu \mathrm{m})$ capillary column and a pulsed flame photometric detector (PFPD).

In addition, the HDS activities evaluation of diesel oil over the prepared NiMo/Al-ZK catalysts were further investigated on a high-pressure hydrogenation micro-reactor using $2.5 \mathrm{wt} \% \mathrm{CS}_{2}$ in cyclohexane for presulfidation. Here, $2.00 \mathrm{~g}$ of the catalysts (40-60 mesh) blended with quartz sand were loaded in a reaction tube with a pipe diameter of $8 \mathrm{~mm}$ and length of about 400 $\mathrm{mm}$. The catalysts were presulfided first and then the pressure and temperature were raised to $5 \mathrm{MPa}$ and $350{ }^{\circ} \mathrm{C}$, respectively. The raw diesel oil was injected into the reactor through a SZB-2 double-piston pump. Then the reaction was carried out at $5 \mathrm{MPa}, 350{ }^{\circ} \mathrm{C}$, and $\mathrm{a}_{2}$ /oil ratio of $300 \mathrm{ml} \mathrm{ml}^{-1}$. When the reaction reached a steady state, the product samples were collected every $2 \mathrm{~h}$. All the liquid samples were collected after the reaction reaching the stable state and were measured by a RPP-2000 SN sulfur and nitrogen analyzer (Taizhou Central Analytical Instruments Co. Ltd. P. R. China).

\section{Results and discussion}

\subsection{XRD results}

In order to control the formation of the building units of ZSM-5 seeds in the preparation process of the ZK composite material, the crystallization process of ZSM-5 was investigated. ZSM-5 samples were synthesized at different crystallization times from $12 \mathrm{~h}$ to $72 \mathrm{~h}$. Their relative crystallinities, which is defined as the area ratio of the characteristic peaks of as-synthesized ZSM-5 with different crystallization times and standard ZSM5 , were calculated. XRD patterns in wide-angle (A) and the relative crystallinity (B) of ZSM-5 are shown in Fig. 2. The ZSM-5 

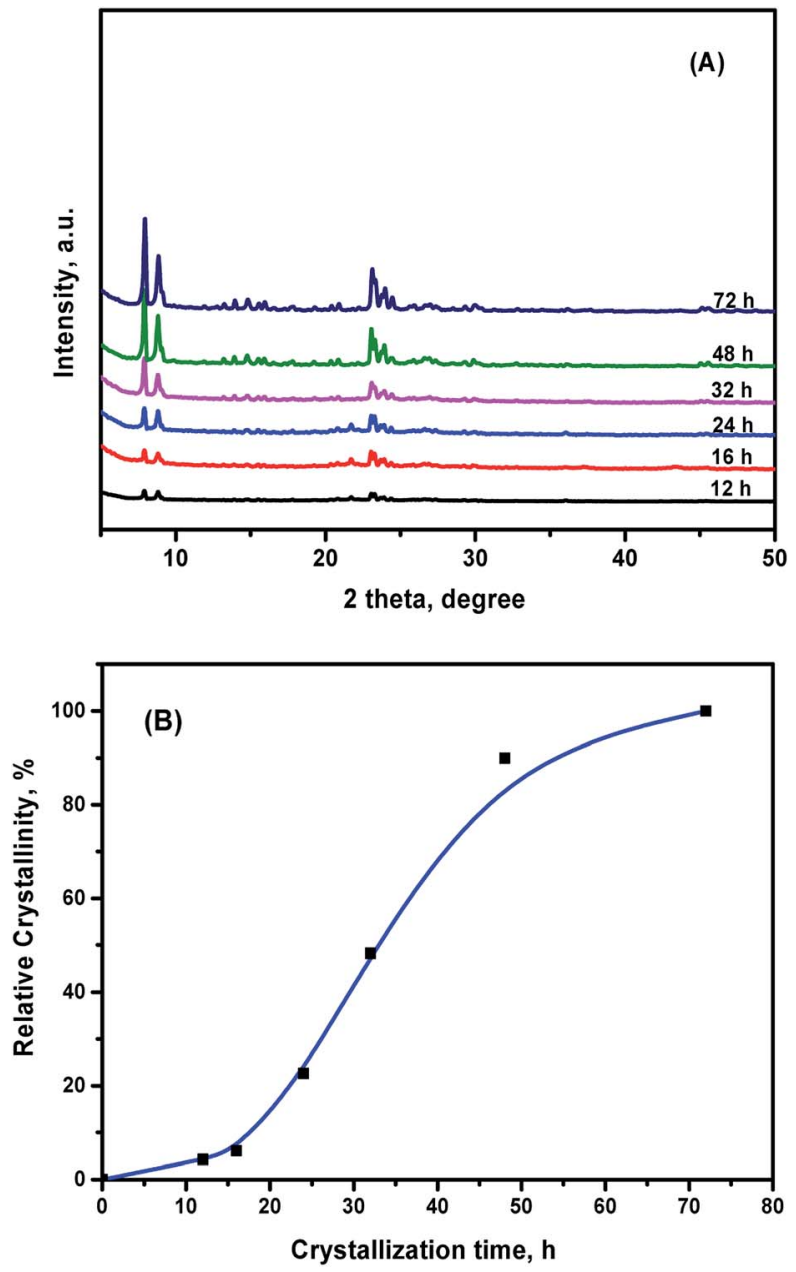

Fig. 2 XRD patterns in wide-angle (A) and the relative crystallinity (B) of ZSM-5 obtained at different crystallization times.

seed obtained at the crystallization time of $12 \mathrm{~h}$ exhibited a relatively weak diffraction peak, indicating that the primary and secondary structural units were beginning to form. The intensities of the diffraction peaks increased as the crystallization time increased, suggesting that nanocrystalline particles of the ZSM-5 crystals were being generated. Therefore, a ZSM-5 crystalline emulsion with the crystallization time of $24 \mathrm{~h}$ could be easily assembled using a mesoporous structuredirecting agent suitable for the synthesis of ZK composite material. With the increasing crystallization time, the ZSM-5 zeolite particles became bigger, and could hardly be assembled in the mesoporous wall. The crystallinity degrees of ZSM-5 with the crystallization time of $48 \mathrm{~h}$ and $72 \mathrm{~h}$ were relatively high, with many sharp peaks clearly observable at $2 \theta=7.9^{\circ}$, $8.8^{\circ}, 20.3^{\circ}, 23.1^{\circ}, 23.9^{\circ}$, and $29.9^{\circ}$, corresponding to the (101), (200), (103), (501), (303), and (303) planes. ${ }^{23}$

XRD patterns of the ZK materials in a small-angle domain with a crystallization time of $24 \mathrm{~h}$ for the ZSM-5 emulsion are shown in Fig. 3. These materials exhibit different characteristic peaks when the amount of $n$-butanol is varied. The results show that different micro-mesoporous structures, such as $p 6 \mathrm{~mm}$

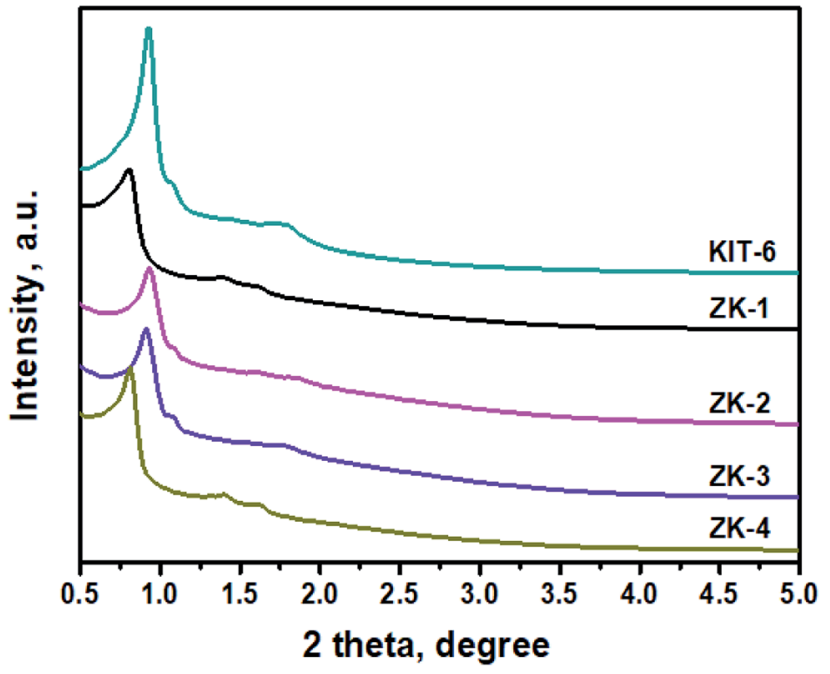

Fig. 3 Small-angle XRD patterns of the different materials.

hexagonal or 3D cubic, were formed with the different butanol addition amounts. ZK-1 and ZK-4 display typical SBA-15 characteristic peaks relating to its (100), (110), and (200) planes, ${ }^{\mathbf{1 6}}$ while ZK-2 and ZK-3 exhibit the characteristic peaks of KIT-6. The results indicate that the composites ZK-1 and ZK-4 may possess the $16 \mathrm{~mm}$ mesostructure of SBA-15, while ZK-2 and ZK-3 may own the cubic $I a \overline{3} d$ structure of KIT- 6 . The obvious peaks at $2 \theta \approx 0.9^{\circ}$ refers to the reflection of (211), while a slightly recognizable hump at around $1.1^{\circ}$ refers to the reflection of (220). In addition, several small uplifts of spectra lines between $1.3^{\circ}$ and $1.9^{\circ}$ under amplification conditions were considered responsible for the lattice planes of (321), (400), (420), and (332). The results indicate that the as-synthesized materials ZK-2 and ZK-3 may own the characteristic structure of KIT- 6 with the body-centered cubic $I a \overline{3} d$ space structure. ${ }^{32}$

\subsection{FTIR results}

The FTIR spectra of ZSM-5, KIT- 6 , and the ZK composites in the domain of $400-1200 \mathrm{~cm}^{-1}$ are displayed in Fig. 4. The framework vibration spectra of ZK samples exhibit the obvious vibration patterns of KIT- 6 centered at $\sim 460,805,970$, and $1080 \mathrm{~cm}^{-1} .{ }^{29}$ The adsorption band around $460 \mathrm{~cm}^{-1}$ represents the $\mathrm{Si}-\mathrm{O}-\mathrm{Si}$ bending vibrations, while the band at $805 \mathrm{~cm}^{-1}$ represents the symmetric stretching vibrations of $\mathrm{Si}-\mathrm{O}-\mathrm{Si}$ bonds. ${ }^{33}$ In addition, the adsorption peak at $1080 \mathrm{~cm}^{-1}$ could be assigned to the asymmetric stretching vibrations of $\mathrm{Si}-\mathrm{O}-\mathrm{Si}$ bonds. The band at $970 \mathrm{~cm}^{-1}$ was ascribed to the defective SiOH group. ${ }^{17}$

Noteworthily, the ZK samples also displayed weak bands at $\sim 570 \mathrm{~cm}^{-1}$, which were a little red-shifted compared with the ZSM-5 characteristic band at $550 \mathrm{~cm}^{-1}$, and these represent the typical vibration bands of five- or six-membered rings of $\mathrm{X}-\mathrm{O}-\mathrm{X}$, where $\mathrm{X}$ can be $\mathrm{Al}$ or $\mathrm{Si}$. Because the $\mathrm{Si}$ or $\mathrm{Al}$ atoms in $\mathrm{X}-\mathrm{O}-\mathrm{X}$ are not as stable as those in the zeolite ZSM-5, the energy required for $\mathrm{X}-\mathrm{O}-\mathrm{X}$ vibration decreases, so the absorption peak at $550 \mathrm{~cm}^{-1}$ was hence red-shifted. ${ }^{34}$ These results demonstrate 


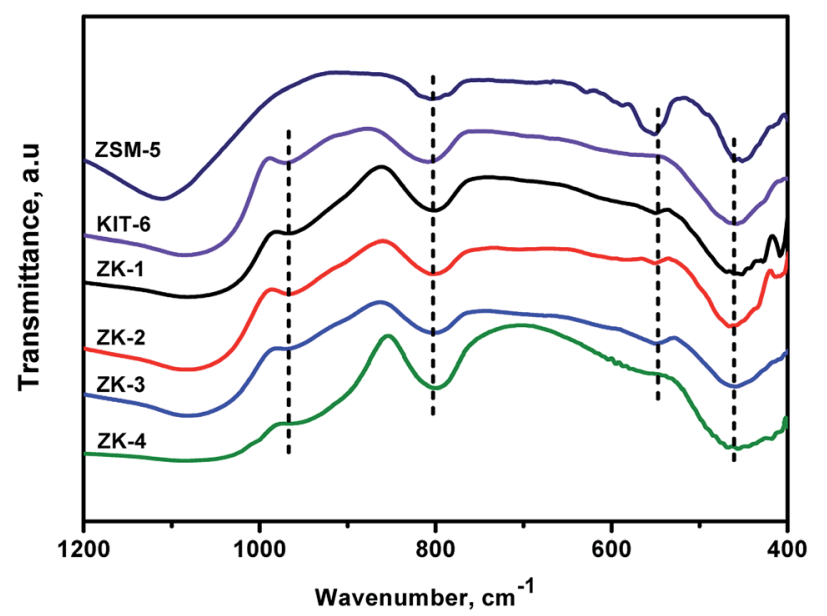

Fig. 4 FTIR spectra of the different materials.

that the primary and secondary structural units of the ZSM-5 zeolite were assembled in a mesoporous structure, thus, a micro-mesoporous ZK material with the characteristic structure of mesoporous KIT-6 and zeolite ZSM-5 was formed. The FTIR results were consistent with the XRD results.

\section{3. ${ }^{27}$ Al MAS NMR}

${ }^{27} \mathrm{Al}$ MAS NMR was carried out to investigate the coordination of $\mathrm{Al}$ atoms in the as-synthesized ZK series supports. As shown in Fig. 5, the sharp peak at about 55 ppm was due to tetrahedrally coordinated $\mathrm{Al}$ atoms in the zeolite framework, ${ }^{35}$ while the weak peak at 0 ppm could be assigned to extra-framework aluminum with octahedrally coordinated $\left(\mathrm{AlO}_{6}\right.$ structural unit). Zeolite ZSM-5 only showed one peak at 55.4 ppm, illustrating that all the $\mathrm{Al}$ atoms were in main framework. A similar phenomenon was observed for the ZK series supports, which exhibited an intense peak at about 55.1 ppm rather than 52.2 ppm as Al-KIT6 (a kind of aluminosilicate) after the incorporation of $\mathrm{Al}$ atoms into KIT- $6 .{ }^{26}$ The results prove the $\mathrm{Al}$ coordinations in $\mathrm{ZK}$

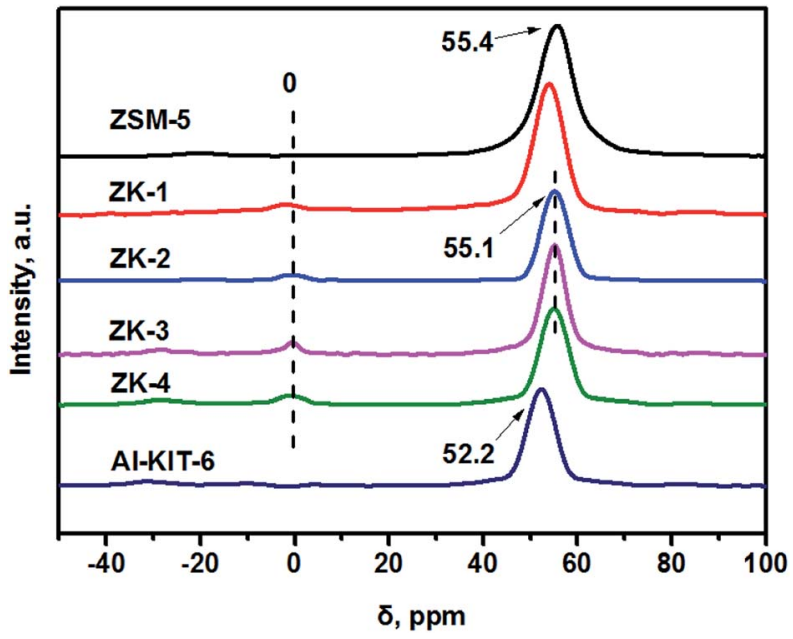

Fig. $5{ }^{27} \mathrm{Al}$ MAS NMR spectra of the as-synthesized materials.

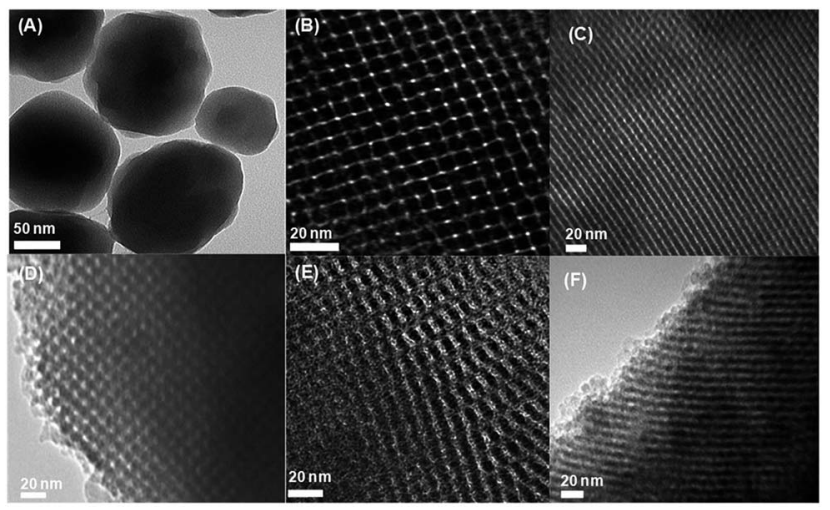

Fig. 6 Typical TEM images of the as-synthesized materials: (A) ZSM-5, (B) KIT-6, (C) ZK-1,(D) ZK-2, (E) ZK-3, (F) ZK-4

materials are the same as that in zeolite ZSM-5, indicating that the mesoporous framework of ZK is assembled by zeolite ZSM-5 primary and secondary building units.

\subsection{TEM results}

Some typical TEM images of the as-synthesized materials are exhibited in Fig. 6. The ZSM-5 particles show a good dispersion and possess a uniform particle size of $\sim 150 \mathrm{~nm} .{ }^{29}$ The representative images of KIT-6 and ZK materials exhibit wellregulated arrays of mesoporous channels. No obvious ZSM-5 particles could be observed in the TEM images of the ZK samples, indicating that no ZSM-5 particle was formed in the ZK composites. From Fig. 6, it can be seen that ZK-1 and ZK-4 exhibit well-ordered hexagonal mesopores with a $\mathrm{p} 6 \mathrm{~mm}$ hexagonal structure, while ZK-2 and ZK-3 show a cubic Ia $\overline{3} d$ mesoporous structure similar to KIT-6. ${ }^{16,22}$ The images show that the structure of the as-synthesized composites depends on the addition amount of $\mathrm{BuOH}$. A high or low molar ratio of $\mathrm{BuOH} /$ $\mathrm{P} 123(\mathrm{BuOH} / \mathrm{P} 123=120$ or 80$)$ leads to the formation of a hexagonal cylindrical porous structure. The TEM images agree well with the XRD results.

\section{5. $\quad \mathrm{N}_{2}$ adsorption-desorption results}

As mentioned above, the amount of $n$-butanol has a significant effect on the pore properties of the synthesized materials. Therefore, the series of ZK materials were characterized by $\mathrm{N}_{2}$ adsorption-desorption. The $\mathrm{N}_{2}$ adsorption-desorption isotherms of the as-synthesized materials are displayed in Fig. 7. Both the KIT-6 and ZK supports exhibited type-IV isotherms with H1-type hysteresis loops, which are typical behaviors of ordered mesoporous structures.

However, compared with KIT-6, the "relative heights" of the hysteresis loops of ZK materials were lower due to the reduction of pore volume, which was caused by the assembly of ZSM-5 zeolite seeds. $\mathrm{Al}_{2} \mathrm{O}_{3}$ also exhibited a type-IV isotherm with a H4-type hysteresis loop, which could be attributed to the intergranular pores. Zeolite ZSM-5 exhibited a type-I isotherm of a microporous material with a small loop at a high relative 

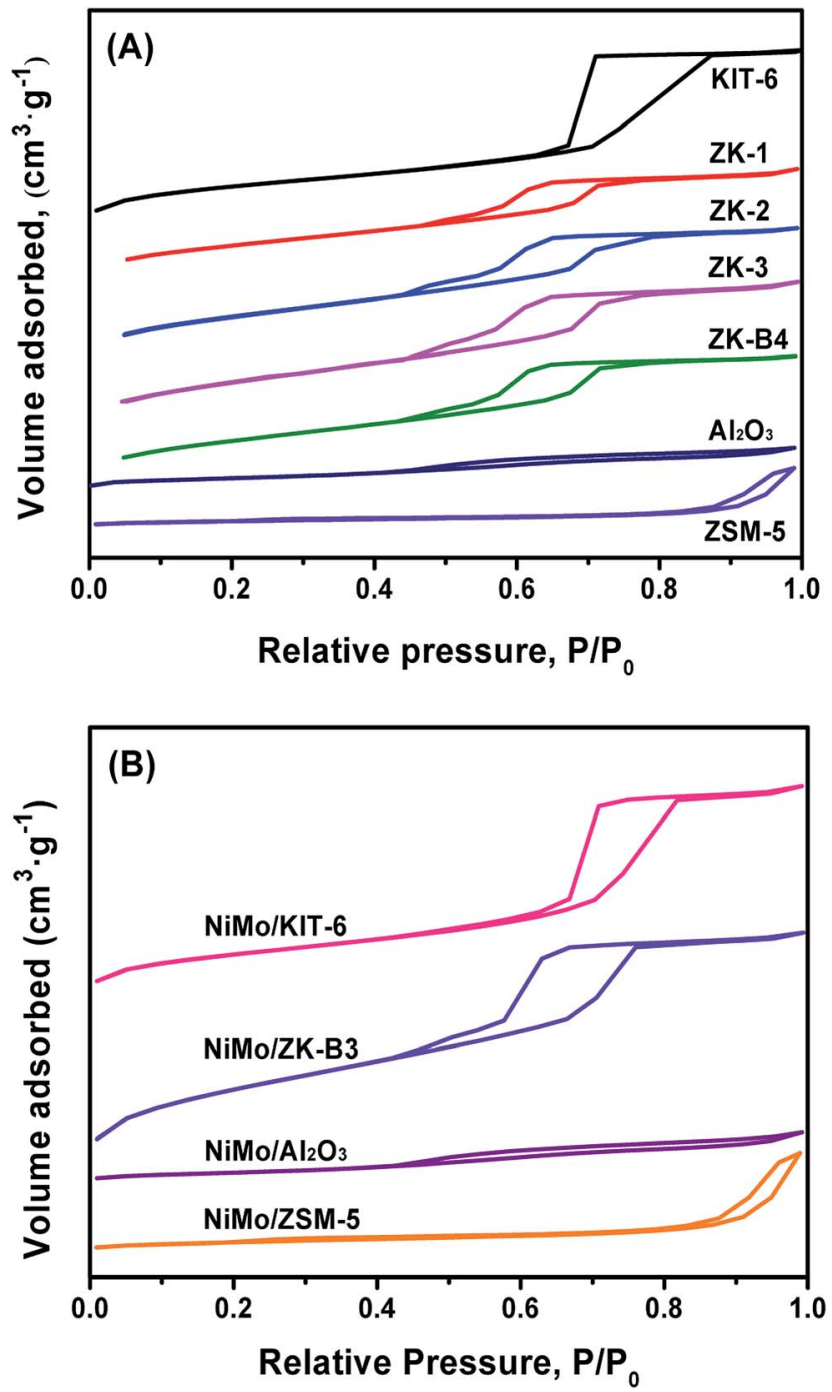

Fig. $7 \quad \mathrm{~N}_{2}$ adsorption-desorption isotherms of the as-synthesized materials (A) and corresponding catalysts (B).

pressure due to the adsorption of intergranular pores between the nano-sized particles.

The pore size distribution (PSD) curves of the different supports are shown in Fig. 8. The KIT-6, ZK composites, and $\mathrm{Al}_{2} \mathrm{O}_{3}$ supports show a narrow PSD, with mesoporous silica KIT6 possessing the largest average pore size. The micro-mesoporous ZK materials exhibited a little smaller pore size than KIT-6, on one hand, this was likely because the ZSM-5 primary and secondary structure were assembled in to a mesoporous wall, which thickens the pore wall and decreases the pore size. On the other hand, this phenomenon can be explained by the pore plugging inside mesoporous channels due to the assembly of some non-uniform-sized nanocrystals of zeolite ZSM-5. Different molar ratios of $\mathrm{BuOH} / \mathrm{P} 123$ could also affect the PSD of this series of materials. The $\mathrm{Al}_{2} \mathrm{O}_{3}$ support had a PSD with an average pore diameter of $3.5 \mathrm{~nm}$, but nevertheless, the ZSM-5 zeolite showed a wider PSD, and no mesoporous channels were discovered.
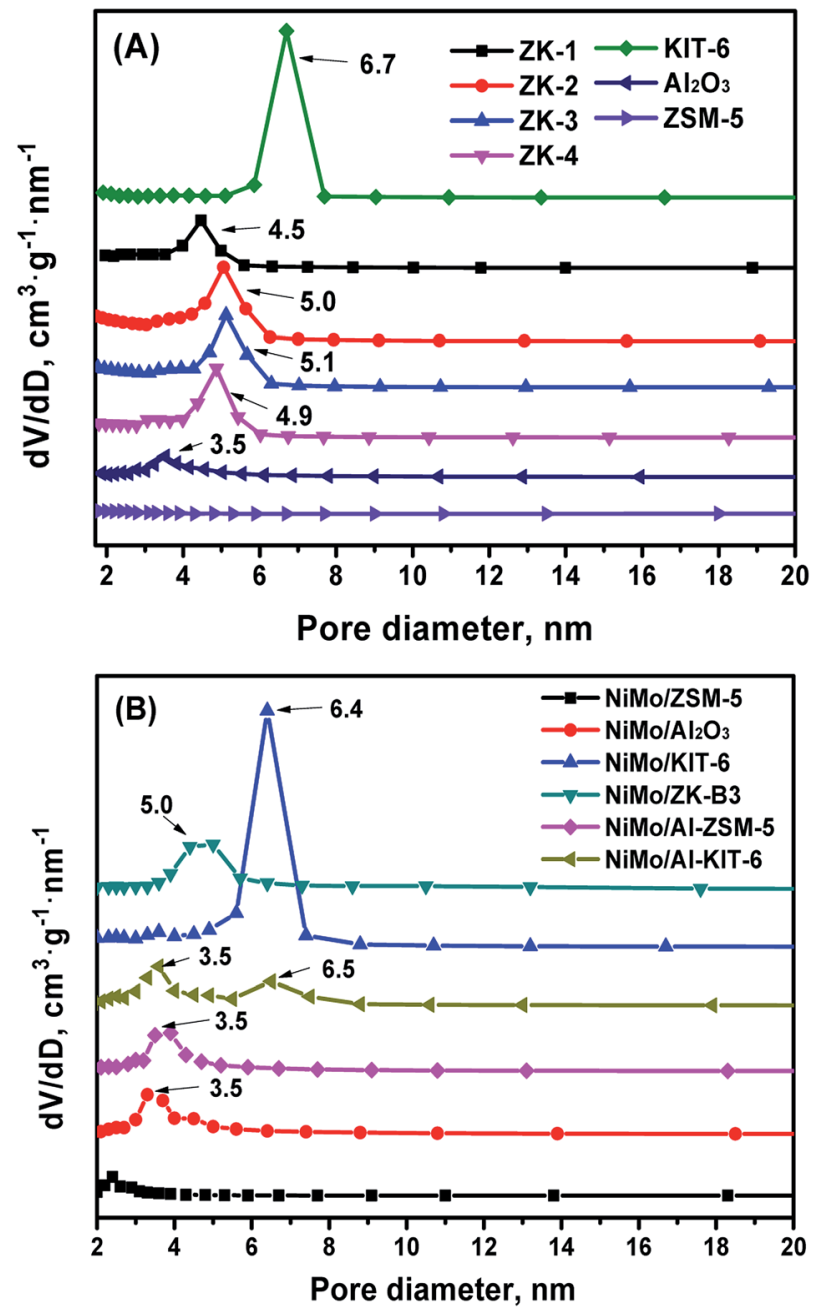

Fig. 8 Pore size distribution of the different supports (A) and corresponding catalysts (B).

The isotherms of all the catalysts were similar to their corresponding supports, while the relative heights of the hysteresis loops were decreased slightly due to the impregnation of active metals. The PSD curves display no obvious changes in average pore size, which demonstrates that the mesoporous structures were reserved after the loading of NiMo species.

The textural properties of the as-synthesized materials and their corresponding catalysts are shown in Table 1. KIT-6 possessed the largest specific area $\left(929 \mathrm{~m}^{2} \mathrm{~g}^{-1}\right)$, pore volume $\left(1.04 \mathrm{~cm}^{3} \mathrm{~g}^{-1}\right)$, and average pore diameter $(6.9 \mathrm{~nm})$. The textural properties of ZK materials showed a decreasing tendency, but these were still more superior to ZSM-5 zeolite. The sample ZK-3 displayed the highest specific area $\left(858 \mathrm{~m}^{2} \mathrm{~g}^{-1}\right)$, largest pore volume $\left(0.90 \mathrm{~cm}^{3} \mathrm{~g}^{-1}\right)$, and an average pore diameter $(4.6 \mathrm{~nm})$, resulting from the difference in the amount of $n$-butanol. It's known that the addition of $n$-butanol has a significant effect on the phase area of the synthesized material, thus a suitable addition of $n$-butanol is beneficial to form a cubic $I a \overline{3} d$ structure. The results indicated that the synthesized ZK material had the best pore structure. Because of the channel blockage of NiMo species in the impregnation process, the specific surface 
Table 1 Texture properties of the as-synthesized supports and the corresponding NiMo catalysts

\begin{tabular}{|c|c|c|c|c|}
\hline Samples & $S_{\mathrm{BET}}{ }^{a}\left(\mathrm{~m}^{2} \mathrm{~g}^{-1}\right)$ & $V_{t}^{b}\left(\mathrm{~cm}^{3} \mathrm{~g}^{-1}\right)$ & $V_{\text {mes }^{c}}^{c}\left(\mathrm{~cm}^{3} \mathrm{~g}^{-1}\right)$ & $d_{\mathrm{BJH}}{ }^{d}(\mathrm{~nm})$ \\
\hline $\mathrm{Al}_{2} \mathrm{O}_{3}$ & 169 & 0.24 & 0.23 & 3.5 \\
\hline ZSM-5 & 304 & 0.43 & - & - \\
\hline ZK-1 & 693 & 0.75 & 0.67 & 4.3 \\
\hline ZK-2 & 811 & 0.86 & 0.76 & 4.5 \\
\hline ZK-3 & 858 & 0.90 & 0.82 & 4.6 \\
\hline NiMo/ZSM-5 & 195 & 0.32 & - & - \\
\hline NiMo/KIT-6 & 470 & 0.77 & 0.72 & 5.9 \\
\hline NiMo/ZK-3 & 437 & 0.52 & 0.47 & 4.2 \\
\hline NiMo/Al-ZSM-5 & 139 & 0.18 & 0.18 & - \\
\hline NiMo/Al-KIT-6 & 151 & 0.26 & 0.26 & 4.0 \\
\hline NiMo/Al-ZK-3 & 151 & 0.22 & 0.22 & 3.5 \\
\hline
\end{tabular}

${ }^{a}$ Calculated by the BET method. ${ }^{b}$ The total pore volume was obtained at a relative pressure of $0.98 .{ }^{c}$ Calculated using the BJH method. ${ }^{d}$ Mesopore diameter calculated by the $\mathrm{BJH}$ method.

area and pore volume of all the catalysts were clearly decreased in comparison with their corresponding supports. Fortunately, the mesoporous structures were not destroyed, which would not affect too much the mass transfer ability.

\subsection{Pyridine-FTIR results}

Fig. 9 shows the FTIR spectra of the different catalysts after pyridine adsorption in the region of $1700-1400 \mathrm{~cm}^{-1}$.

The peaks appearing at $1540 \mathrm{~cm}^{-1}$ and $1450 \mathrm{~cm}^{-1}$ could be designated as Brønsted and Lewis acid sites, respectively. The peak around $1490 \mathrm{~cm}^{-1}$ stands for the pyridine co-adsorption of both Brønsted and Lewis acid, meanwhile, the band located around $1610 \mathrm{~cm}^{-1}$ belongs to a Lewis acid. ${ }^{3,36,37}$ The amounts of Lewis and Brønsted acid sites on the different catalysts are listed in Table 2. The NiMo/ZSM-5 owns the largest amounts of acid sites among all the catalysts. NiMo/KIT-6 showed a much lower strength of acid, just slightly higher than $\mathrm{NiMo} / \mathrm{Al}_{2} \mathrm{O}_{3}$ because of the electroneutral framework of KIT-6. No Brønsted acids were detected over NiMo/KIT- 6 and $\mathrm{NiMo} / \mathrm{Al}_{2} \mathrm{O}_{3}$. The composite material ZK combines the advantages of ZSM- 5 and
Table 2 Amounts and distributions of Lewis and Brønsted acid sites of different catalysts

\begin{tabular}{|c|c|c|c|c|c|c|c|c|}
\hline \multirow[b]{2}{*}{ Catalysts } & \multicolumn{4}{|c|}{$473 \mathrm{~K}\left(\mu \mathrm{mol} \mathrm{g}{ }^{-1}\right)$} & \multicolumn{3}{|c|}{$623 \mathrm{~K}\left(\mu \mathrm{mol} \mathrm{g}{ }^{-1}\right)$} & \multirow[b]{2}{*}{$\mathrm{B} / \mathrm{L}$} \\
\hline & $\mathrm{L}$ & B & $\mathrm{L}+\mathrm{B}$ & $\mathrm{B} / \mathrm{L}$ & $\mathrm{L}$ & B & $\mathrm{L}+\mathrm{B}$ & \\
\hline $\mathrm{NiMo} / \mathrm{Al}_{2} \mathrm{O}_{3}$ & 92 & - & 92 & 0 & 39 & - & 39 & 0 \\
\hline NiMo/ZSM-5 & 342 & 89 & 431 & & 88 & 21 & 109 & \\
\hline NiMo/KIT-6 & 43 & - & 43 & 0 & 37 & - & 37 & 0 \\
\hline NiMo/ZK-1 & 129 & 25 & 154 & 0.19 & 46 & 10 & 56 & 0.22 \\
\hline NiMo/ZK-2 & 140 & 30 & 170 & 0.21 & 51 & 11 & 62 & 0.22 \\
\hline NiMo/ZK-3 & 135 & 32 & 167 & 0.24 & 53 & 13 & 66 & 0.25 \\
\hline NiMo/ZK-4 & 125 & 23 & 148 & 0.18 & 42 & 9 & 51 & 0.21 \\
\hline
\end{tabular}

KIT-6, so the NiMo catalysts supported on ZK retained the Brønsted acid sites, which enhanced the acidity of the material compared with the NiMo catalyst supported on pure KIT-6. The total acid amounts decrease in the order: NiMo/ZSM-5 $>\mathrm{NiMo} /$ $\mathrm{ZK}-2>\mathrm{NiMo} / \mathrm{ZK}-3>\mathrm{NiMo} / \mathrm{ZK}-1>\mathrm{NiMo} / \mathrm{ZK}-4>\mathrm{NiMo} / \mathrm{Al}_{2} \mathrm{O}_{3}>$ NiMo/KIT-6. The B/L ratios of the total acid and the medium and strong acid of the ZK-supported catalysts follow the order:
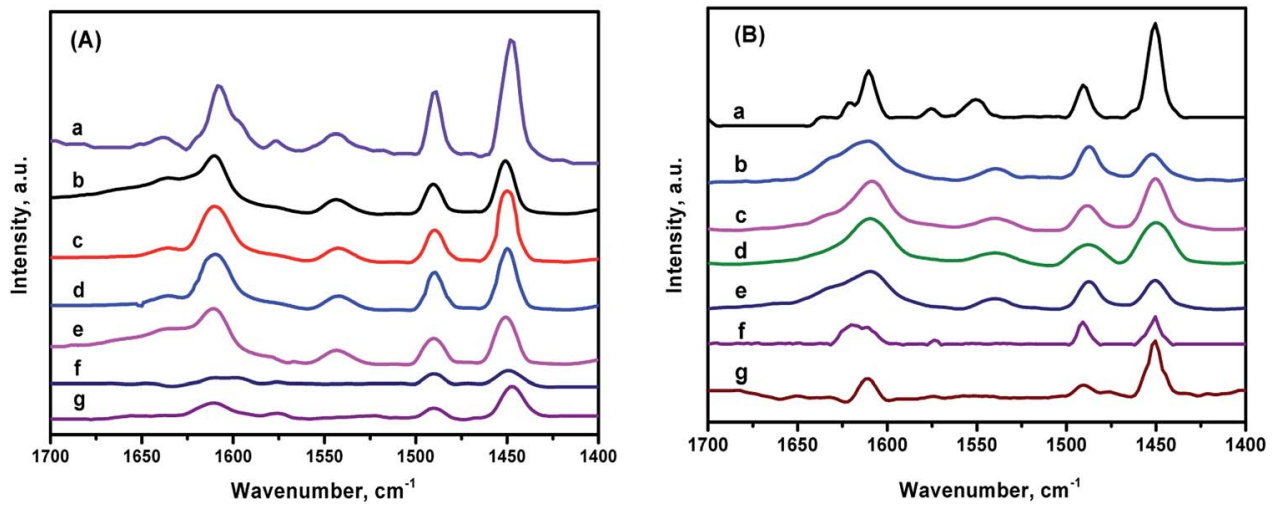

Fig. 9 Pyridine-FTIR spectra of different catalysts: (a) NiMo/ZSM-5, (b) NiMo/ZK-1 (c) NiMo/ZK-2, (d) NiMo/ZK-3, (e) NiMo/ZK-4, (f) NiMo/KIT-6, (g) $\mathrm{NiMo} / \mathrm{Al}_{2} \mathrm{O}_{3}$ after degassing at $473 \mathrm{~K}(\mathrm{~A})$ and $623 \mathrm{~K}(\mathrm{~B})$. 


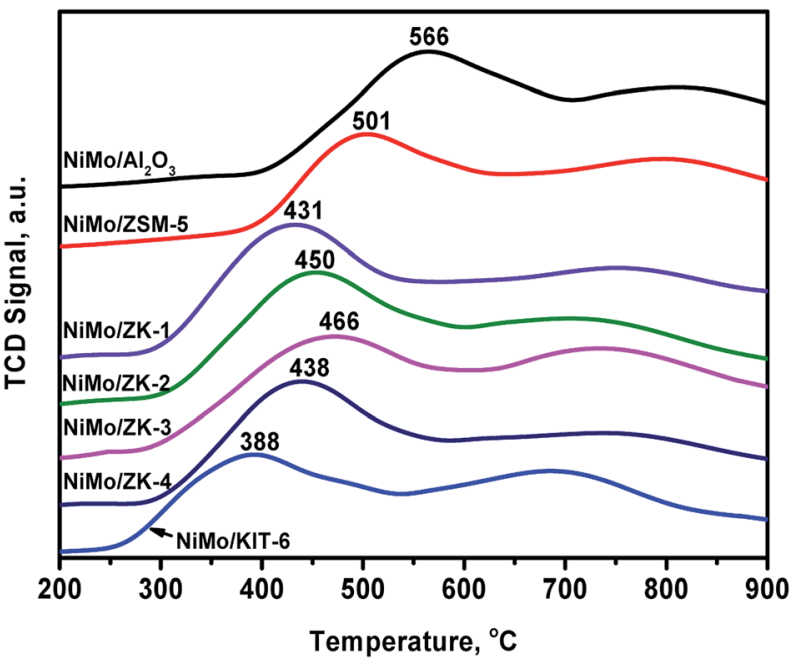

Fig. $10 \mathrm{H}_{2}$-TPR curves of the supported NiMo catalysts.

NiMo/ZK-3 $(0.24,0.25)>$ NiMo/ZK-2 $(0.21,0.22)>$ NiMo/ZK-1 $(0.19,0.22)>\mathrm{NiMo} / \mathrm{ZK}-4(0.18,0.21)$, demonstrating that the incorporation of ZSM-5 structural units into the porous wall of KIT-6 is beneficial for the formation of B acid sites. Meanwhile, $\mathrm{Al}$ atoms all existed in the ZSM-5 structural units, with the results also indicating that the $\mathrm{Al}$ atoms were embedded in the porous framework, which is in accordance with the ${ }^{27} \mathrm{Al}$ MAS NMR results.

\section{7. $\mathrm{H}_{2}$-TPR results}

$\mathrm{H}_{2}$-TPR curves of different catalysts are exhibited in Fig. 10. The profiles of all the catalysts exhibited two reduction peaks in the ranges of $380-570{ }^{\circ} \mathrm{C}$ and $650-850{ }^{\circ} \mathrm{C}$. The former peak could be attributed to the reduction of octahedral Mo species $\left(\mathrm{Mo}^{6+}+2 \mathrm{e}^{-}\right.$ $\left.\rightarrow \mathrm{Mo}^{4+}\right) \cdot{ }^{38}$ The high-temperature reduction peak was due to the complete reduction of $\mathrm{Mo}^{4+}$ species $\left(\mathrm{Mo}^{4+}+2 \mathrm{e}^{-} \rightarrow \mathrm{Mo}^{0}\right) \cdot{ }^{38}$ The temperatures of different peaks strongly depend on the metalsupport interaction force (MSI). The weaker the metal-support interaction force, the lower is the reduction temperature.

It can be seen from Fig. 10 that $\mathrm{NiMo} / \mathrm{Al}_{2} \mathrm{O}_{3}$ possessed the strongest MSI with a reduction temperature of $566{ }^{\circ} \mathrm{C}$, while NiMo/KIT- 6 possessed the weakest, with a reduction temperature of $388{ }^{\circ} \mathrm{C}$. The first reduction temperatures follow the order: NiMo/ $\mathrm{Al}_{2} \mathrm{O}_{3}\left(566^{\circ} \mathrm{C}\right)>\mathrm{NiMo} / \mathrm{ZSM}-5\left(501{ }^{\circ} \mathrm{C}\right)>\mathrm{NiMo} / \mathrm{ZK}-3$ $\left(466{ }^{\circ} \mathrm{C}\right)>\mathrm{NiMo} / \mathrm{ZK}-2\left(450{ }^{\circ} \mathrm{C}\right)>\mathrm{NiMo} / \mathrm{ZK}-4\left(438^{\circ} \mathrm{C}\right)>\mathrm{NiMo} / \mathrm{ZK}-$ $1\left(431^{\circ} \mathrm{C}\right)>\mathrm{NiMo} / \mathrm{KIT}-6\left(388^{\circ} \mathrm{C}\right)$, demonstrating that the MSIs of the $\mathrm{NiMo} / \mathrm{ZK}$ catalysts had a proper MSI in comparison to $\mathrm{NiMo} / \mathrm{Al}_{2} \mathrm{O}_{3}$, NiMo/ZSM-5 and NiMo/KIT-6.

\subsection{Raman results}

Raman spectroscopy is a very effective method to evaluate the dispersion of active components on supports. ${ }^{39}$ The Raman spectra are shown in Fig. 11 for all the supported NiMo catalysts, where five unambiguous peaks can be recognized. These catalysts show obvious peaks around $948 \mathrm{~cm}^{-1}$ and $844 \mathrm{~cm}^{-1}$, which could be assigned to the $\mathrm{NiMoO}_{4}$ precursor phase. ${ }^{38,40}$

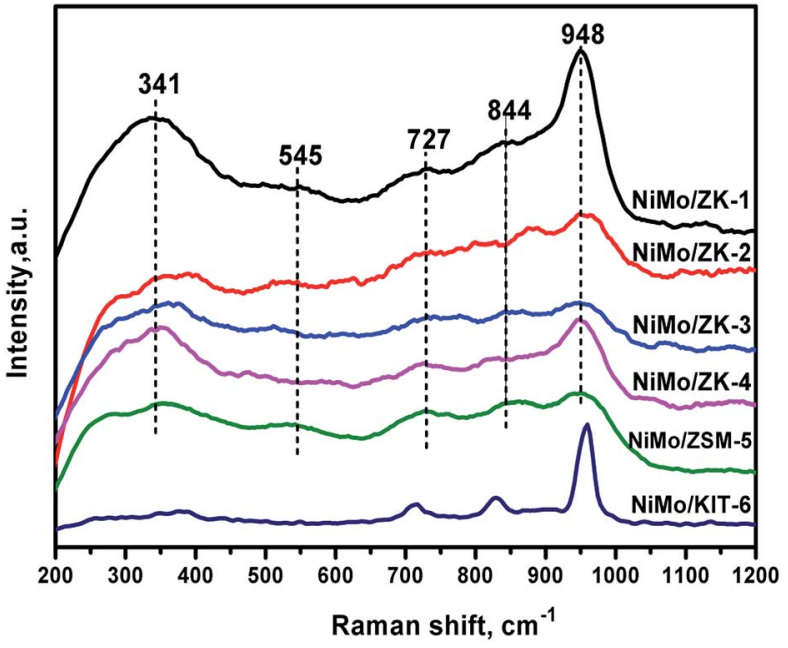

Fig. 11 Raman spectra of the different catalysts.

The band at $948 \mathrm{~cm}^{-1}$ belongs to the symmetric and asymmetric $\mathrm{Mo}=\mathrm{O}$ terminal stretching vibrations of various surface polymolybdate species, indicating highly dispersed octahedral $\mathrm{Mo}^{6+}$ surface species, which come from $\mathrm{Mo}_{7} \mathrm{O}_{24}{ }^{6-}$ species. ${ }^{41}$ These molybdenum oxide species are deemed to have a weak interaction between supports and active metals, thus contributing to their higher reducibility in HDS reactions. ${ }^{38}$ The intensities of bands around $948 \mathrm{~cm}^{-1}$ follow the sequence: NiMo/ZK-1 > NiMo/ZK-4 > NiMo/ZK-2 > NiMo/ZK-3, which demonstrates that the MSIs decrease in the inverse order. NiMo/ZK-1 possessed the similar MSIs as NiMo/KIT-6, which was too weak, while the MSIs of NiMo/ZK-2, NiMo/ZK-3, and NiMo/ZK-4 catalyst were promoted. These result agree well with the $\mathrm{H}_{2}$-TPR results. The band at $844 \mathrm{~cm}^{-1}$ could be ascribed to the asymmetric stretching mode of the Mo-O-Mo bridge bond of the octahedral molybdate species. ${ }^{41}$ The bands at $727 \mathrm{~cm}^{-1}$ could be attributed to the $\alpha-\mathrm{NiMoO}_{4}$ phase. ${ }^{42}$ The vibration band at $545 \mathrm{~cm}^{-1}$ results from the stretching model of $\mathrm{Al}-\mathrm{O}(\mathrm{Mo}-\mathrm{O}-\mathrm{Al}) .{ }^{43}$ The broad peak at $341 \mathrm{~cm}^{-1}$ represents the bending model of terminal $\mathrm{Mo}=\mathrm{O}$ of octahedral $\mathrm{MoO}_{4}{ }^{2-}$ species. ${ }^{44}$

\subsection{HRTEM results}

It is commonly accepted that the activities of catalysts are greatly related to the state of $\mathrm{MoS}_{2}$ distribution on the supports. ${ }^{45}$ To date, HRTEM characterization has been considered a relatively impactful measurement, and enables to obtain the lengths and stacking degree of $\mathrm{MoS}_{2}$ crystallites over the catalysts. $^{46}$ The representative HRTEM micrographs are displayed in Fig. 12. The average length $L_{\mathrm{av}}$ and stacking layer number $N_{\mathrm{av}}$ of the $\mathrm{MoS}_{2}$ crystallites were calculated based on eqn (1): ${ }^{27}$

$$
L_{\mathrm{av}}=\frac{\left(\sum_{i=1}^{n} n_{\mathrm{i}} l_{\mathrm{i}}\right)}{\left(\sum_{i=1}^{n} n_{\mathrm{i}}\right)} ; N_{\mathrm{av}}=\frac{\left(\sum_{i=1}^{n} n_{\mathrm{i}} N_{\mathrm{i}}\right)}{\left(\sum_{i=1}^{n} n_{\mathrm{i}}\right)}
$$




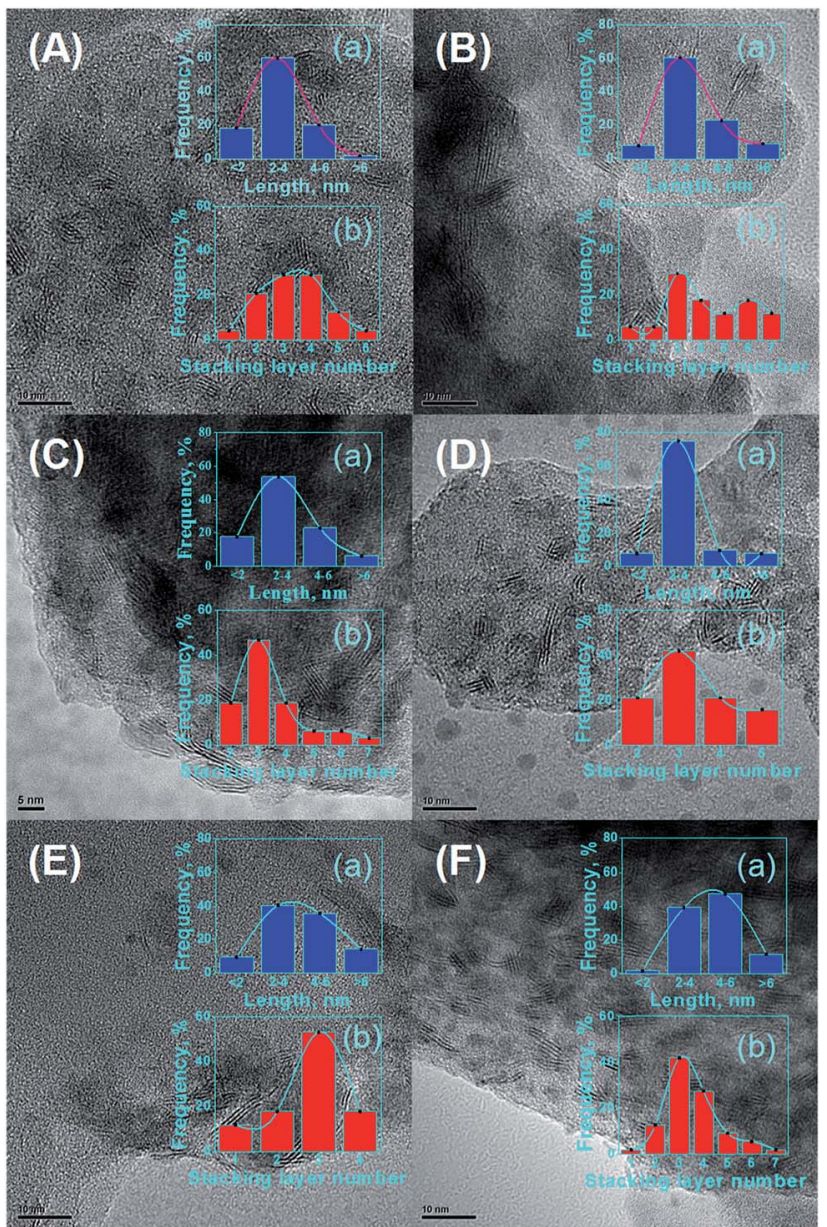

Fig. 12 HRTEM images, (a) length, and (b) stacking layer number of NiMoS slabs on different sulfided catalysts: (A) NiMo/ZK-1, (B) NiMo/ ZK-2, (C) NiMo/ZK-3, (D) NiMo/ZK-4, (E) NiMo/ZSM-5, (F) NiMo/KIT-6.

where $l_{\mathrm{i}}$ represents the length of slabs, $n_{\mathrm{i}}$ is the number of $\mathrm{MoS}_{2}$ crystallites with the particular length $l_{\mathrm{i}}$, and $N_{\mathrm{i}}$ represents the number of stacking layers of the $\mathrm{MoS}_{2}$ crystallite i.

The dispersion degree of Mo $\left(f_{\text {Mo }}\right)$ was calculated from eqn $(2)::^{27}$

$$
f_{\mathrm{Mo}}=\frac{\mathrm{Mo}_{\text {edge }}}{\mathrm{Mo}_{\text {total }}}=\frac{\sum_{i=1}^{t}\left(6 n_{\mathrm{i}}-6\right)}{\sum_{i=1}^{t}\left(3 n_{\mathrm{i}}{ }^{2}-3 n_{\mathrm{i}}+1\right)}
$$

where $\mathrm{Mo}_{\text {edge }}$ is the number of Mo atoms located on the edges, $\mathrm{Mo}_{\text {total }}$ is the total number of Mo atoms, $n_{i}$ is the number of Mo atoms along one edge of a $\mathrm{MoS}_{2}$ slab determined from its length $\left(L=3.2\left(2 n_{\mathrm{i}}-1\right) \AA\right)$, and $t$ is the total number of slabs.

The textural properties are closely related to the dispersion and sulfuration degree of the active phases. Different specific surface areas and pore structures would lead to the formation of a different morphology of NiMos crystallite, which would have a significant influence on the catalytic performance. ${ }^{47}$ It has been reported that the Ni-Mo-S active phase has two different types of structure, resulting in a notable difference in reaction activity. ${ }^{48,49}$ The structure with low intrinsic activity is designate as type-I Ni-Mo-S phase, while the type-II Ni-Mo-S phase has an improved intrinsic activity, which favors HDS reaction processes. ${ }^{50} \mathrm{~A}$ short length and appropriate stacking degree of NiMoS slabs are helpful to form the type-II Ni-Mo-S active phase. ${ }^{51}$ The NiMo/ZSM-5 catalyst with the lowest stacking degree of NiMoS slab would form more type-I Ni-Mo-S phase, and hence NiMo/ZSM-5 displays the lowest HDS activity. The NiMo/KIT-6 catalyst with the highest stacking degree of NiMoS crystallites could form more type-II active phases, which is beneficial for HDS reactions, but its $L_{\mathrm{av}}$ is not short. NiMo/ZK catalysts possess a more appropriate stacking degree and a shorter average length of NiMoS slabs compared with the catalysts NiMo/KIT-6 and NiMo/ZSM-5. A lower degree of stacking layer number of NiMoS restricts the planar adsorption of the reactants, therefore inhibiting the catalytic performances of catalysts. ${ }^{52,53}$ However, it must be noted that only the external staking layer of NiMoS would reveal particular edge sites. If the stacking number is overtopped, the amount of corner and edge sites would decrease.

The statistical results $L_{\mathrm{av}}$ and $N_{\mathrm{av}}$ of the different catalysts are shown in Table 3. The dispersion degrees of active sites $\left(f_{\text {Mo }}\right)$ show the trend: NiMo/ZK-3 > NiMo/ZK-2 > NiMo/ZK-4 > NiMo/ ZK-1 > NiMo/ZSM-5 > NiMo/KIT-6. The results are due to the combined effects between the pore structure properties and metal-support interaction forces. The open pore structure favors the diffusion of active species to promote the sulfide degree of active metals, while a suitable metal-support interaction can be propitious to the diffusion of active species. However, if the metal-support interaction is too strong, Ni ions can form spinel structures with $\mathrm{Al}_{2} \mathrm{O}_{3}$, which affects the dispersion and sulfuration of active components. The superior pore structure of micro-mesoporous composite materials and appropriate metal-support interaction in the catalysts, such as NiMo/ZK-3, enable a better diffusion of NiMoS crystallites than NiMo supported on pure ZSM-5 and KIT-6. Overall, the NiMo/ ZK-3 catalyst had a better NiMoS dispersion and possessed more active edge sites, which were favorable for HDS processes.

\subsection{Catalyst evaluation}

3.10.1 HDS results of DBT. The DBT conversions obtained over the different NiMo-supported catalysts with the LHSV ranging from 150 to $20 \mathrm{~h}^{-1}$ are shown in Fig. 13.

It can be seen that the conversion of DBT clearly increases as the LHSV decreases. Almost all the composite-supported catalysts exhibited better HDS performances than the catalysts

Table 3 Average length $\left(L_{\text {av }}\right)$ and stacking layer number $\left(N_{\text {av }}\right)$ of NiMoS crystallites

\begin{tabular}{llll}
\hline Catalyst & $L_{\mathrm{av}}(\mathrm{nm})$ & $N_{\mathrm{av}}$ & $f_{\text {Mo }}$ \\
\hline NiMo/ZK-1 & 3.94 & 3.45 & 0.33 \\
NiMo/ZK-2 & 3.62 & 3.19 & 0.37 \\
NiMo/ZK-3 & 3.18 & 3.36 & 0.42 \\
NiMo/ZK-4 & 3.79 & 3.24 & 0.34 \\
NiMo/ZSM-5 & 4.92 & 3.06 & 0.28 \\
NiMo/KIT-6 & 5.02 & 3.50 & 0.27
\end{tabular}




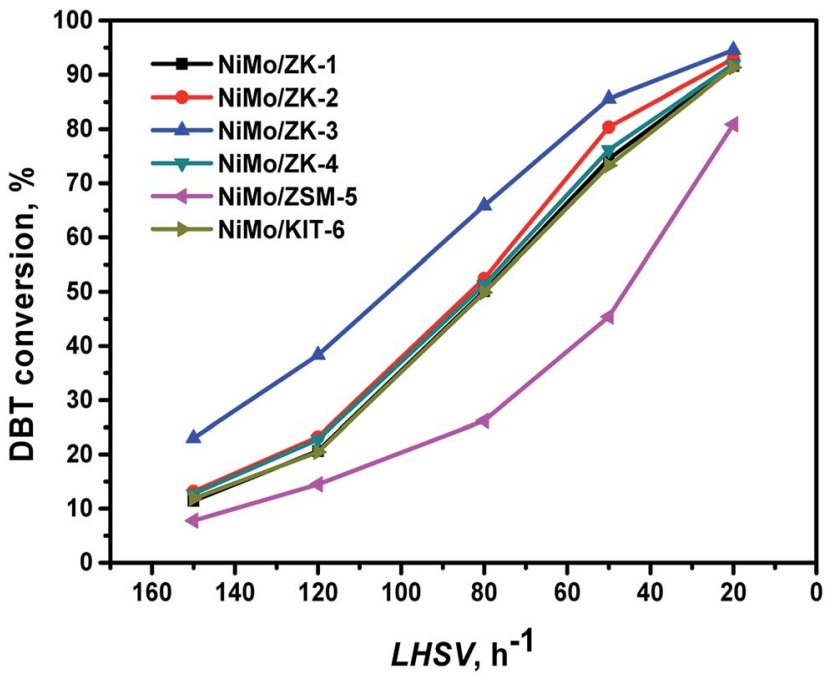

Fig. 13 DBT conversions of different NiMo-supported catalysts in the HDS reaction.

supported on pure ZSM-5 and KIT-6. The catalytic activities of these catalysts kept to the order: NiMo/ZK-3 > NiMo/ZK-2 > NiMo/ZK-4 > NiMo/ZK-1 > NiMo/KIT-6 > NiMo/ZSM-5. The DBT conversion of NiMo/ZK-3 at LHSV $=150 \mathrm{~h}^{-1}$, which was about twice that of NiMo/KIT- 6 and more than three times that of NiMo/ZSM-5. This is because the addition of $n$-butanol changes the texture properties of $\mathrm{ZK}$ composites. The addition of $n$ butanol changes the pore diameter and pore volume, which directly affect the ability of diffusion, resulting in the differences in the distribution of the active metal phase. NiMo/ZK-3 with the largest specific area, pore volume, and pore diameter exhibited the highest DBT conversion among this series of catalysts.

To clarify the effect of the amount of $n$-butanol on the reaction pathways of DBT, the reaction samples over different catalysts with a total DBT conversion of around 50\% were analyzed by GC-MS chromatography. The products distributions are shown in Table 4. Five products: tetrahydrodibenzothiophene (THDBT), cyclohexen-1-ylbenzene (CHEB), phenylcyclohexane (CHB), biphenyl (BP), and iso-phenyl-

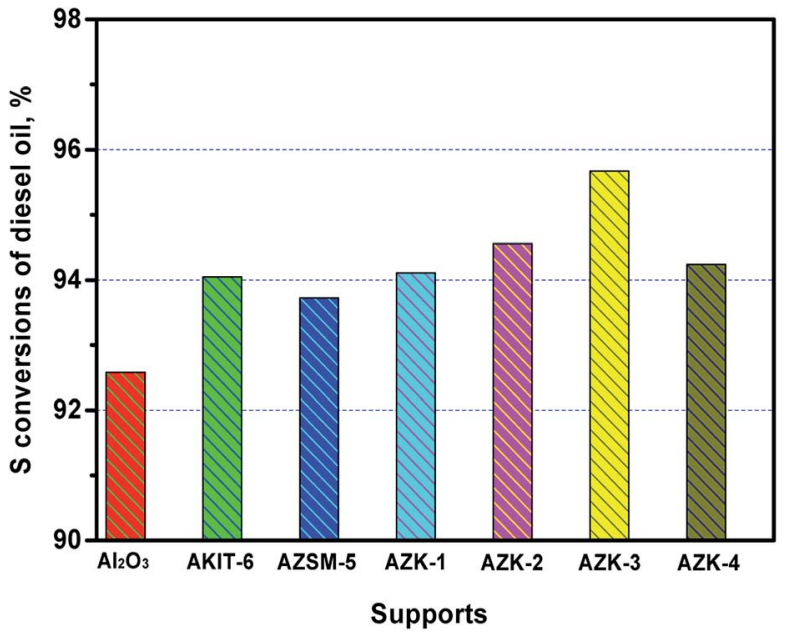

Fig. 14 S conversions of NiMo catalysts on different supports.

hexadiene (Iso-PHDi) were detected over the series of NiMo/ ZK catalysts, similar to the DBT HDS products over NiMo/BK catalysts reported by Zhang et al. ${ }^{\mathbf{2 6}}$ Since no Brønsted acid sites exist in the NiMo/KIT-6 catalyst, the isomerization products were not found in the HDS products of the NiMo/KIT-6 catalyst, as shown in Table 4 . BP is the final product of the DDS pathway, and the DDS pathway is the primary route for the HDS of DBT. THDBT, CHEB, and CHB are sequentially generated in the HYD pathway, ${ }^{54,55}$ and a part of Iso-PHDi was formed from CHEB under the isomerization of the Brønsted acid. CHB accounts for the largest proportion of the products of the HYD pathway. The BP selectivities of the series of catalysts follow the order: NiMo/ZK-3 (72.1\%) > NiMo/ZK-2 (65.1\%) > NiMo/ZK-4 $(62.2 \%)>\mathrm{NiMo} / \mathrm{ZK}-1$ (60.5\%). NiMo/ZK-3 exhibited the highest DBT HDS activity. The higher catalytic performance and selectivity of the DDS route could be attributed to the superior pore properties of the supports.

3.10.2 HDS results of diesel oil. In order to validate the superior activity of the micro-mesoporous material-supported catalysts, fluid catalytic cracking (FCC) of diesel was used as HDS feed oil with a sulfur content of $1013 \mu \mathrm{g} \mathrm{g}{ }^{-1}$. The HDS performances of these catalysts are shown in Fig. 14. All the

Table 4 Catalytic performance for the HDS of DBT over NiMo-supported catalysts

\begin{tabular}{|c|c|c|c|c|c|c|}
\hline \multirow[b]{3}{*}{ Catalysts } & \multicolumn{5}{|c|}{ Product selectivity (\%) } & \multirow[b]{3}{*}{$\mathrm{HYD}$ DDS ratio ${ }^{a}(\%)$} \\
\hline & \multicolumn{4}{|l|}{ HYD } & \multirow{2}{*}{$\frac{\mathrm{DDS}}{\mathrm{BP}}$} & \\
\hline & THDBT & CHEB & $\mathrm{CHB}$ & Iso-PHDi & & \\
\hline NiMo/ZK-1 & 3.6 & 5.1 & 24.5 & 6.3 & 60.5 & 65.3 \\
\hline NiMo/ZK-2 & 2.6 & 5.9 & 19.4 & 7.0 & 65.1 & 53.6 \\
\hline NiMo/ZK-3 & 1.9 & 6.1 & 12.3 & 7.6 & 72.1 & 38.7 \\
\hline NiMo/ZK-4 & 2.8 & 5.6 & 22.9 & 6.5 & 62.2 & 60.8 \\
\hline NiMo/ZSM-5 & 2.6 & 0.6 & 37.1 & 9.4 & 50.3 & 98.8 \\
\hline NiMo/KIT-6 & 4.0 & 6.1 & 32.0 & - & 57.9 & 72.7 \\
\hline
\end{tabular}

${ }^{a}$ Equal to the total selectivities of THDBT, CHEB, CHB, and Iso-PHDi. 
catalysts supported on $\mathrm{Al}-\mathrm{ZK}\left(4 \mathrm{Al}_{2} \mathrm{O}_{3}: 1 \mathrm{ZK}\right.$, wt\%) mixtures exhibited higher activity than NiMo/AZSM-5, NiMo/AKIT-6, and $\mathrm{NiMo} / \mathrm{Al}_{2} \mathrm{O}_{3}$. This is because the $\mathrm{ZK}$ composites combine the advantages of ZSM-5 and KIT- 6 materials and possess proper acidity, and a large pore size and volume. NiMo/AZSM-5 and NiMo/AKIT-6 have larger specific areas and pore volumes than $\mathrm{NiMo} / \mathrm{Al}_{2} \mathrm{O}_{3}$ (Table 1). Furthermore, the acidity of ZSM-5 material and the pore size of KIT- 6 are better than that of $\mathrm{Al}_{2} \mathrm{O}_{3}$, and these advantages can favor the removal of sulfur-containing compounds. The HDS activities of NiMo supported on this series of AZK mixtures followed the order: NiMo/AZK-3 > NiMo/ AZK-2 > NiMo/AZK-4 > NiMo/AZK-1. This is in agreement with the HDS results of DBT.

\section{Conclusions}

In this research, a novel micro-mesoporous composite material ZK was prepared by assembling ZSM- 5 crystals into a wellordered mesoporous framework. The directional synthesis of micro-mesoporous composites with a controllable modulation of the pore structures was achieved by adjusting the addition amount of $n$-butanol. The texture properties of the assynthesized composites with different addition amounts of $n$ butanol showed obvious differences with the increasing molar ratio of $\mathrm{BuOH} / \mathrm{P} 123$. A high or low molar ratio of $\mathrm{BuOH} / \mathrm{P} 123$ $(\mathrm{BuOH} / \mathrm{P} 123=120$ or 80$)$ led to the formation of a hexagonal cylindrical pore structure. When $\mathrm{BuOH} / \mathrm{P} 123=100, \mathrm{ZK}-3$ showed the typical cubic $I a \overline{3} d$ mesoporous structure, and possessed the largest specific area $\left(858 \mathrm{~m}^{2} \mathrm{~g}^{-1}\right)$ and pore volume $\left(0.90 \mathrm{~cm}^{3} \mathrm{~g}^{-1}\right)$. The ZK material combined the advantages of KIT- 6 and ZSM-5, possessing as large specific area, pore size, and pore volume as KIT-6 silica; moreover, it also had a similar acid distribution and a little weaker acidity of the ZSM-5 zeolite.

The NiMo/ZK catalysts were evaluated using DBT and diesel oil as raw materials. The NiMo/ZK-3 catalyst showed the highest catalytic activity in the HDS of DBT. The HDS reaction network of DBT over NiMo/ZK catalysts had two reaction routes: DDS and HYD pathways. The DDS pathway was the main route of the HDS reaction. BP and CHB were the main products of the DDS and HYD pathways, respectively. The molar ratio of BuOH/P123 had an effect on HYD selectivity, whereby when $\mathrm{BuOH} / \mathrm{P} 123=100$, the BP selectivity reached up to $72.1 \%$. Furthermore, the NiMo/AlZK-3 catalyst showed superior catalytic performance in the HDS of diesel oil. ZK-3supported NiMo catalysts exhibited excellent DBT and diesel HDS performances because of the excellent textural property, moderate MSI, and relatively high $\mathrm{B} / \mathrm{L}$ ratios of the catalysts, and due to the highly dispersed NiMoS active phases. These results are meaningful for the future applications of industrial HDS catalysts.

\section{Conflicts of interest}

There are no conflicts to declare.

\section{Acknowledgements}

The authors acknowledge the financial supports from the National NSFC (No. 21503152, No. 21276277, No. U1463207), the Natural Science Foundation of Hubei Province (2014CFA090), the Opening Project of the Key Laboratory of Green Chemical Process (Wuhan Institute of Technology) (GCP201401), the Scientific Research Foundation of Wuhan Institute of Technology (K201640 and K201760), and the Graduate Innovation Fund of Wuhan Institute of Technology (No. CX2016085). The authors are grateful to Dr Xilong Wang et al. (China University of Petroleum (Beijing)) for the help in the evaluation of catalysts.

\section{References}

1 S. T. Oyama, H. Y. Zhao, H. J. Freund, et al., J. Catal., 2012, 285, 1-5.

2 L. Yang, X. Li, A. Wang, et al., J. Catal., 2015, 330, 330-343. 3 S. Shan, P. Yuan, W. Han, et al., J. Catal., 2015, 330, 288-301. 4 J. Xiong, W. S. Zhu, H. P. Li, et al., Green Chem., 2008, 10, 641-646.

5 J. Xiong, W. S. Zhu, H. M. Li, et al., AIChE J., 2013, 59, 46964704.

6 M. Ali and S. Natalia, Catal. Sci. Technol., 2018, 8, 2323-2332.

7 Y. Okamoto, M. Breysse, G. M. Muralidhar, et al., Catal. Today, 2003, 86, 1.

8 W. Fu, L. Zhang, T. Tang, et al., J. Am. Chem. Soc., 2011, 133, 15346-15349.

9 H. Liu, Y. P. Li, C. L. Yin, et al., Appl. Catal., B, 2016, 198, 493507.

10 H. Wu, A. Duan, Z. Zhao, et al., RSC Adv., 2017, 7, 4434044347.

11 D. Z. Han, X. Li and L. Zhang, Microporous Mesoporous Mater., 2012, 158, 1-6.

12 H. Zhang, L. Han, A. Duan, et al., RSC Adv., 2017, 7, 2803828047.

13 P. Schacht, S. Ramírez and J. Ancheyta, Energy Fuels, 2009, 23, 4860-4865.

14 F. X. Chen, L. Huang, X. J. Yang, et al., Mater. Lett., 2013, 109, 299-301.

15 F. Jin, S. J. Huang, S. F. Cheng, et al., Catal. Sci. Technol., 2015, 5, 3007-3016.

16 D. Y. Zhao, J. L. Feng, B. . F. Chmelka, et al., Science, 1998, 279, 548-552.

17 J. Liu, L. Yu, Z. Zhao, et al., J. Catal., 2012, 285, 134-144.

18 O. Y. Gutiérrez, F. Pérez, G. A. Fuentes, et al., Catal. Today, 2008, 130, 292-301.

19 S. F. Chen, J. L. Li, Y. H. Zhang, et al., Catal. Sci. Technol., 2014, 4, 1005-1011.

20 S. F. Chen, J. L. Li, Y. J. Zhang, et al., Top. Catal., 2014, 57, 437-444.

21 F. He, J. Q. Luo, S. T. Liu, et al., Chem. Eng. J., 2016, 294, 362370.

22 T. W. Kim, F. Kleitz, et al., J. Am. Chem. Soc., 2005, 127, 76017610.

23 M. Choi, K. Na, J. Kim, et al., Nature, 2009, 461, 246-249. 
24 K. Soni, B. S. Rana, A. K. Sinha, et al., Appl. Catal., B, 2009, 90, 55-63.

25 Q. Y. Yu, L. Zhang and R. Guo, Fuel Process. Technol., 2017, 159, 76.

26 D. Zhang, A. Duan, Z. Zhao, et al., J. Catal., 2010, 274, 273286.

27 A. J. Duan, T. S. Li, Z. Zhao, et al., Appl. Catal., B, 2015, 165, 763-773.

28 Q. Y. Yu, L. Zhang, R. Guo, et al., Fuel Process. Technol., 2017, 159, 76-87.

29 H. D. Wu, A. J. Duan, Z. Zhao, et al., J. Catal., 2014, 317, 303317.

30 R. V. Grieken, J. L. Sotelo, J. M. Menéndez, et al., Microporous Mesoporous Mater., 2000, 39, 135-147.

31 F. Kleitz, S. H. Choi and R. Ryoo, Chem. Commun., 2003, 9, 2136-2137.

32 Y. Wan and D. Y. Zhao, Chem. Rev., 2007, 107, 2821-2860.

33 V. Umamaheswari, M. Palanichamy and V. Murugesan, J. Catal., 2002, 210, 367-374.

34 Y. Liu, W. Z. Zhang, T. J. Pinnavaia, et al., Angew. Chem., Int. Ed., 2001, 40, 1255-1257.

35 E. Lippmaa, A. Samoson and M. Magi, J. Am. Chem. Soc., 1986, 108, 1730.

36 J. A. Z. Pieterse, S. V. Reyes, L. Domokos, et al., J. Catal., 1999, 187, 518-520.

37 M. Maache, A. Janin, J. C. Lavalley, et al., Zeolites, 1993, 13, 419-426.

38 R. L. Cordero, F. G. Llambias and A. L. Agudo, Appl. Catal., 2000, 74, 125-136.
39 W. Li, G. D. Meitzner and E. Lglesia, J. Catal., 2000, 191, 373383.

40 P. Biswas, P. Narayanasarma, A. K. Dalai, et al., Ind. Eng. Chem. Res., 2011, 50, 7882-7895.

41 H. Hu, I. E. Wachs and S. R. Bare, J. Phys. Chem. C, 1995, 99, 10897-10910.

42 Y. Wang, G. Xiong, X. Liu, et al., J. Phys. Chem. C, 2008, 112, 17265-17271.

43 W. Han, P. Yuan, Y. Fan, et al., J. Mater. Chem., 2012, 22, 25340-25353.

44 X. Wang, Z. Zhao, P. Zheng, et al., J. Catal., 2016, 344, 680691.

45 T. E. Klimova, D. Valencia and J. A. Mendoza-Nieto, J. Catal., 2013, 304, 29-46.

46 D. Valencia and T. Klimova, Appl. Catal., B, 2013, 129, 137145.

47 O. Y. Gutieérrez, S. Singh, J. A. Lercher, et al., ACS Catal., 2014, 4, 1487-1499.

48 S. Kasztelan, H. Toulhoat, J. Grimblot, et al., Appl. Catal., 1984, 13, 127-135.

49 H. Topsøe, Appl. Catal., A, 2007, 322, 3-8.

50 D. Gao, A. Duan, X. Zhang, et al., Appl. Catal., B, 2015, 165, 269-284.

51 Y. Li, D. Pan, C. Xu, et al., J. Catal., 2012, 286, 124-136.

52 F. Besenbacher, M. Brorson, J. Kibsgaard, et al., Catal. Today, 2008, 130, 86-96.

53 O. Gutiérrez and T. J. Klimova, Catalysis, 2011, 281, 50-62.

54 E. Marina and P. Roel, J. Catal., 2004, 225, 417-427.

55 Y. Y. Sun and P. Roel, J. Catal., 2009, 267, 193-201. 